\title{
Preparing new normal: the health literacy assessment on the Covid-19
}

\author{
Supriyati Supriyati ${ }^{1,2^{*}}$, Dian Kurnia Anggraeny ${ }^{3}$, Theodora Monica Carissa ${ }^{3}$, \\ Abicintha Pramesti Sheila ${ }^{3}$, Shiefa Annisa Qisthi ${ }^{3}$, Maulidiannisa Rianti ${ }^{3}$, and \\ Tommy Roshan ${ }^{3}$
}

Submitted:

January 12th, 2021

Accepted:

January 19th, 2021

Published:

January 27th, 2021

${ }^{1}$ Center of Health Behavior and Promotion, Faculty of Medicine, Public Health, and Nursing, Universitas Gadjah Mada, Indonesia

${ }^{2}$ Department of Health Behavior, Environment, and Social Medicine, Faculty of Medicine, Public Health, and Nursing, Universitas Gadjah Mada, Indonesia

${ }^{3}$ Medical Program, Faculty of Medicine, Public Health, and Nursing, Universitas Gadjah Mada, Indonesia

*Correspondence:

supriyati@ugm.ac.id

\begin{abstract}
Purpose. This study was aimed to assess the health literacy of the COVID-19 for both of the knowledge level on the Covid-19 and the health protocol compliance by the medical and the non-medical student. Method This rapid action research was conducted from July-August 2020. Respondents were Indonesian students who voluntarily fulfilled the online questionnaire. A total 208 respondents participated in this study (104 students for each group). Data analysis was performed by using chi square. Furthermore, an animation video was developed and published through Instagram TV as the follow up assessment. Result. The result showed that the medical students had better knowledge $(41.8 \%$ vs $33.2 \%$, $p$-value $=0.000)$ and health protocol compliance (6.3\% vs $2.4 \%, p$-value $=0.049)$ than the non-medical students. The lowest compliance towards health protocol of the both groups was the physical distancing. Moreover, the health education regarding physical distancing by using animation video had reached audiences. According to the audiences' comments, the video made them aware of the importance of physical distancing. Conclusion It was important to improve health literacy for preparing new normal, and it should be developed based on the need assessment.
\end{abstract}

Keywords: new normal; health literacy; health protocol compliance; physical distancing; Covid-19

\section{INTRODUCTION}

The global pandemic of the coronavirus disease (Covid-19) needs prevention and control actions to reduce the impact of the Covid-19 [1]. The impact of the Covid-19 is not limited to the health sector, but it has reached out to all sectors [2]. WHO strongly encourages people to take simple precautions such as regularly and thoroughly cleaning hands with an alcohol-based hand rub or soap and water; maintaining distance from each other; avoiding going to crowded places; avoiding touching face; wearing a fabric mask; isolating from others when feeling unwell and seeking medical attention if needed.

Health education and risk communications had been done to improve community health literacy toward the Covid-19. Furthermore, new normal was introduced as the global health education and global strategy to address the impact of the Covid-19 on the economic aspect [3]. Unfortunately, there is a lot of misinformation regarding the Covid-19 and the prevention strategy [4]. It described the poor health literacy of the Covid-19 among population. The poor health literacy and the misinformation are leading to the wrong practice of the prevention behavior and 
raising the stigma on the Covid-19 [5,6]. Nevertheless, poor health literacy usually becomes an underestimated problem in public health [6]. Health literacy is the ability to acquire, understand, and use the information in a sound and ethical manner. In addition, research on how to develop community health literacy is lacking.

Public health intervention or strategic health promotion should be developed to improve health literacy and decrease the impact of the Covid-19 [7]. Health promotion is contextual and a good health promotion should be designed based on the need assessment result [8,9]. The population health literacy is the social responsibility of the group who has a high level of health literacy, not limited to the health services provider [6]. Students are the potential agent of change for better health [10]. Furthermore, students has social responsibility for helping the surrounding community to solve their problem, including the poor health literacy problem [3].

This study was aimed to assess the students' health literacy of the Covid-19, whereas consist of the knowledge level on the Covid-19 and their compliance towards health protocol by the medical and the non-medical group. Besides, this study also develops a health intervention as the follow up of the assessment results.

\section{METHODS}

This study was applied action research design [11]. This study was conducted in July-August 2020. The survey and the following intervention was done online, since the pandemic Covid-19 suggested people to apply physical distancing. Respondents were Indonesian students with inclusion criteria such as the maximum age was 30 years old, used social media, and were willing to fulfill the online questionnaire in the certain period. The consecutive sampling had been performed in this research. There were 208 students involved in this study, who consisted of 104 respondents with medical background and 104 respondents with non-medical background. The medical background referred to the students from the medical cluster (medicine, nursing, health nutrition, public health, pharmacy, as well as dentistry) and health professions.

Data was collected by using an online questionnaire in four days, through numerous social media platforms (Instagram, LINE Messaging application, WhatsApp Messaging application). The questionnaire was developed by a research team according to the health protocol guideline of the Indonesian Ministry of Health (the third edition). The question to assess the student health literacy consisted of the knowledge level on the Covid-19 and the compliance toward health protocol of the Covid-19 prevention (physical distancing, use of a mask, and hand washing). Besides, the age, gender, and medical background were assessed in this study. Data were analyzed with the bivariate method using chi-square test to compare the variables.

As the follow up of the survey results, researchers had developed an animation video on the physical distancing. The animation video was created through the website application PowToon with a duration of 107 seconds and distributed through Instagram TV to reach the targeted audiences. Physical distancing was chosen as the key message of the health education because physical distancing had the worst score from the both assessment (the knowledge on the Covid-19

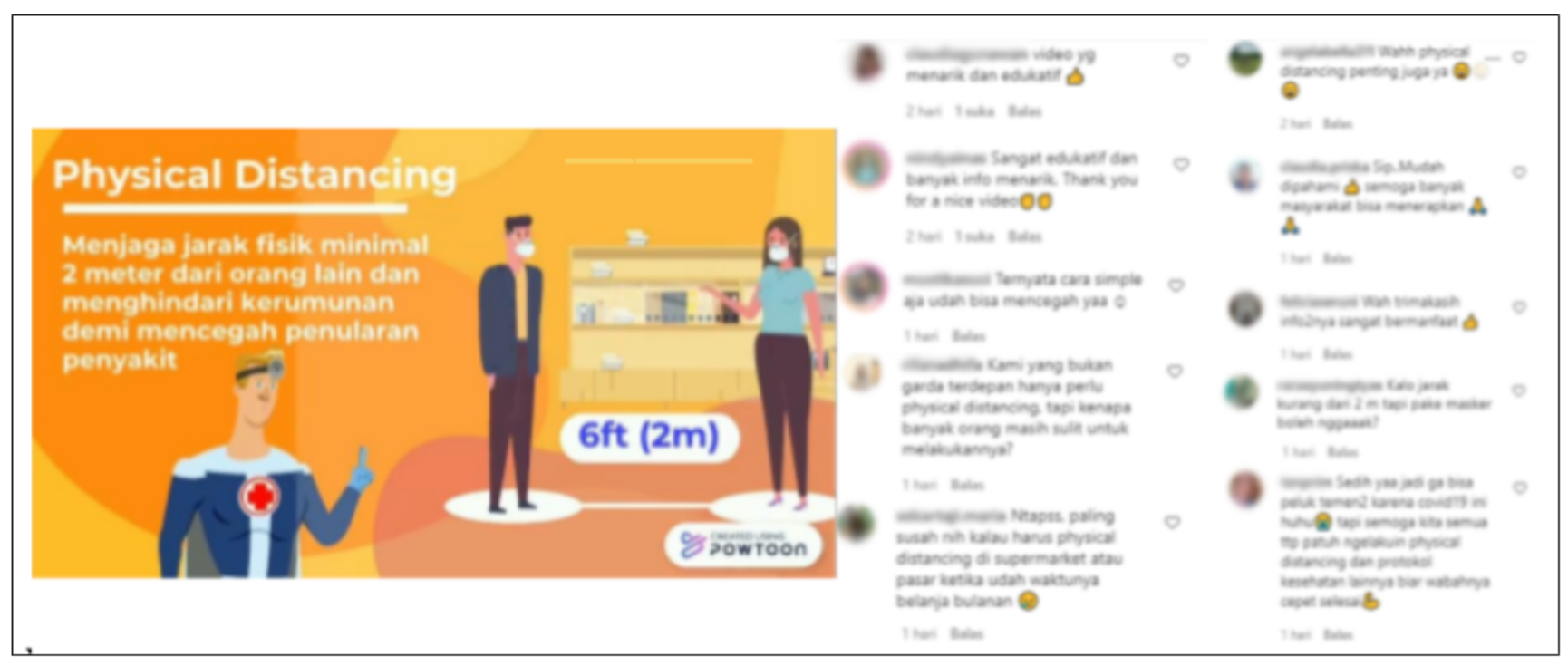

Figure 1. the screenshot of the video campaign and the response of the target audience 
and the compliance toward the health protocol of the Covid-19 prevention).

Moreover, this study was approved by the Medical and Health Research Ethics Committee of Faculty of Medicine, Public Health, and Nursing Universitas Gadjah Mada (no: KE/FK/0903/EC/2020). Besides, respondents had signed the informed consent before fulfilling the online questionnaire.

\section{RESULTS}

Figure 1 shows the number of viewers, the likes, and comments of the animation video on how the health education media reached the target audiences. There were 694 views, 158 likes, and 36 comments of the video within the 24 hours since the video was uploaded. Moreover, the comments were positive and showed the audience's interest in the message.

Table 1 shows that most of respondents were female (66.8\%), and belonging to the age group 18-25 years (82.7\%). Most of respondents had a high level of knowledge on the Covid-19 (58.7\%). Fortunately, respondents who had a medical background had a high level of the knowledge on the Covid-19.

Table 2 showed that there was a significant difference between medical students and non-medical students on the knowledge level of the Covid-19 (p-value $=0.000)$. Most of the medical students $(83.6 \%)$ had a high level of the knowledge on the Covid-19. Meanwhile, only one third (33.6\%) of the non-medical students had a high level of the knowledge on the Covid-19.

Table 1. Sociodemographic characteristic $(\mathrm{N}=208)$

\begin{tabular}{lc}
\hline Characteristics & $\%$ \\
\hline Gender & 33.2 \\
$\quad$ Male & 66.8 \\
$\quad$ Female & \\
Background & 50.0 \\
$\quad$ Medical & 50.0 \\
$\quad$ Non-Medical & \\
Age $\quad$ & 8.2 \\
15-17 years old & 82.7 \\
18-25 years old & 9.1 \\
26-30 years old &
\end{tabular}

Table 2. The knowledge level on the Covid-19, by educational background*

\begin{tabular}{llll}
\hline \multicolumn{3}{l}{ Education background } \\
\hline $\begin{array}{l}\text { Knowledge level } \\
\text { on the Covid-19 }\end{array}$ & Medical & $\begin{array}{l}\text { Non-med } \\
\text { ical }\end{array}$ & Total \\
\hline High & 83.6 & 33.6 & 58.7 \\
Poor & 16.4 & 66.4 & 41.3 \\
\hline Total & $104(100.0)$ & $\begin{array}{l}104 \\
(100.0)\end{array}$ & 100.0 \\
\hline * P Value $=0.000$ & & &
\end{tabular}

Table 3 shows that most respondents had good practice for wearing a mask and hand washing $(84.6 \%$ and $77.9 \%$ respectively). Both the medical students and the non-medical students usually use a mask when they go outside their home and or meet with other people and wash their hands before and after their activities. Indeed, no one of them has ever used a mask and or never performed hand washing. All of the medical students had very good practice in wearing a mask with $94.2 \%$ of them always wearing a mask, and the rest were often wearing a mask. No one of the medical students who had poor practice used the use mask health protocol (rarely and never wearing a mask category). On the other hand, there were only $10.5 \%$ of students $(6.7 \%$ of the medical students and $3.8 \%$ of the non-medical students) who were always keeping $>2$ meters distance. Most of them applied physical distance with 1-2 meters distance (51.9\%). Moreover, there was $4.8 \%$ of the non-medical students ( 5 out of 104 respondents) who never keep distance in their daily activities.

Surprisingly, most of the students (both from the medical and the non-medical group) had poor compliance toward health protocol (91.4\%). Nevertheless, there was a significant difference in the level of compliance toward health protocol between the medical and the non-medical group, with p-value 0.049.

This study showed that there were several factors that contributed to the poor compliance toward health protocols among students. They were (1) lack of awareness (48.6\%), (2) lack of trusted information (39.4\%), (3) unaccustomed to the new adaptation of living (29.8\%), (4) had not experienced COVID-19 personally (10.1\%), (5) regulations that were deemed indecisive (7.2\%), and (6) problems relating economic reasons (5.3\%). Unfortunately, lack of awareness was the biggest one. 
Table 3. The student compliance toward the health protocol, by education background*

Education background

\begin{tabular}{llr}
\hline Medical & Non- \\
$(\mathrm{n}=104)$ & Medical \\
\hline
\end{tabular}

\section{Health Protocol practice}

High Compliance

12.6

4.8

Poor compliance

87.6

Mask wearing

Always wears a mask

94.2

Often wears a mask

Rarely wears a mask

0

Never wear a mask

0

\section{Hand washing}

Always wash hands

before/after activity

Often wash hands

Wash hands occasionally

Never wash hands

0

Physical distancing

Keeping $>2$ meter distance

Keeping 1-2 meter distance

Occasion gather in groups

Never keep distance

0 and the intervention was done by a research team and was reached out to the target audiences online.

\section{DISCUSSIONS}

This study demonstrates that the medical students had a better understanding of Covid-19 and also had a better compliance toward health protocol regarding Covid-19. Generally, students (both medical and non-medical group) had a poor level of compliance toward health protocol. Unfortunately, lack of awareness was the main factor that contributed to the poor compliance toward health protocol among students.

Moreover, physical distancing had the lowest score of compliance among the health protocols (use a mask, hand washing, and physical distancing). Indeed, some non-medical students never applied physical distancing in their daily activities. On the other hand, wearing a mask had the highest level of compliance from both groups. Both the medical and non-medical students' group had good practice on the mask wearing, whether they use fabric mask or medical mask. The Indonesian students also had a good practice on hand washing.

This study showed that the non-medical students had poor health literacy, including the knowledge on the Covid-19 and the level of compliance toward health protocol. Health literacy is closely related with healthy behavior [12]. Health information exposure is needed to improve health literacy. Hence, the health behavior will be better. In this study, the medical students had higher health literacy since they were exposed to health information in their daily activities as the medical students. Nevertheless, one third of the non-medical students had a good knowledge of the Covid-19 and part of them adhered to Covid-19 prevention behavior. There were multiple variable influences on the knowledge level on health, including social relation [13]. Social relation will increase the opportunity to expose the health information [14].

Lack of awareness was led to the adherence to Covid-19 prevention behavior in this study. Lack of awareness correlates with health literacy. Health literacy is the predictor of the Covid-19 awareness and compliance [15]. Furthermore, health literacy increases community engagement toward health program [16-18]. Health literacy determines the community knowledge toward the health program and the community participation [18]. Health literacy increases community awareness of the health problem and will let community compliance and participation [19]. Health literacy is a social capital for preparing new normal in this pandemic Covid-19. Health literacy is a long term investment for better health [15]. 
Physical distancing is very important behavior to prevent the spreading of Covid-19. Unfortunately, it is not easy to keep 2 meters distance in our daily activities. The practice of physical distancing from both medical and non-medical students was the lowest rate in comparison to the other aspects of other health protocols. As the follow up, the animation video on the importance of the physical distancing and the way to practice physical was created and published through Instagram TV. The animation video and the Instagram TV were chosen as the communication media and channel that is appropriate for students. The effective health education and promotion must be considered the target audience characteristic $[8,9,17,20]$.

These findings have relevance to public health actors who develop and deliver policies and programs addressing health promotion and disease prevention. Lack of awareness leads to poor health behavior. The findings support the importance of health literacy improvement. Furthermore, developing a health literacy strategy should be based on the assessment results.

\section{CONCLUSION}

The student's health literacy on the Covid-19 was different between medical and non-medical students. Both the knowledge and the compliance toward the health protocol of the medical students was higher than the non-medical students. Unfortunately, students had poor compliance toward health protocol due to lack of awareness. Physical distancing was the hardest health protocol to obey. Additionally, the animation video on the physical distancing was reached out to the target audiences through Instagram TV and the health education designed based on the need assessment result gained positive response from the target audiences. Social media such as Instagram TV was an alternative communication channel to improve health literacy in the pandemic Covid-19 era.

\section{REFERENCES}

1. Prasetyo YT, Castillo AM, Salonga LJ, Sia JA, Seneta JA. Factors affecting perceived effectiveness of COVID-19 prevention measures among Filipinos during Enhanced Community Quarantine in Luzon, Philippines: Integrating Protection Motivation Theory and extended Theory of Planned Behavior. Int J Infect Dis. 2020;99: 312-323.

2. Supriyati. Gerak Relawan Covid-19: Tanggung jawab Sosial Individu dan Masyarakat In: Winanti PS, Mas'udi W, editors. Tata Kelola Penanganan Covid-19 di Indonesia: Kajian Awal. Yogyakarta: UGM Press. 2020.
3. Jamaludin S, Azmir NA, Mohamad Ayob AF, Zainal N. COVID-19 exit strategy: Transitioning towards a new normal. Ann Med Surg (Lond). 2020;59: 165-170.

4. Mokhtari H, Mirzaei A. The tsunami of misinformation on COVID-19 challenged the health information literacy of the general public and the readability of educational material: a commentary. Public Health. 2020;187: 109-110.

5. Duan W, Bu H, Chen Z. COVID-19-related stigma profiles and risk factors among people who are at high risk of contagion. Soc Sci Med. 2020;266: 113425.

6. Paakkari L, Okan O. COVID-19: health literacy is an underestimated problem. Lancet Public Health. 2020;5: e249-e250.

7. Nussbaumer-Streit B, Mayr V, Dobrescu AI, Chapman A, Persad E, Klerings I, et al. Quarantine alone or in combination with other public health measures to control COVID-19: a rapid review. Cochrane Database Syst Rev. 2020 [cited 20 Jan 2021]. doi:10.1002/14651858.CD013574.pub2

8. Riekert KA, Ockene JK, Pbert L. The Handbook of Health Behavior Change, 4th Edition. Springer Publishing Company; 2013.

9. Snelling AM. Introduction to Health Promotion. John Wiley \& Sons; 2014.

10. Supriyati S, Wicaksana AL, Sundari E, Pangastuti HS, Dewi FST. Why do we need to empower university staff and students for tackling the non-communicable diseases? Journal of Community Empowerment for Health. 2021.

11. Whitehead D, Taket A, Smith P. Action research in health promotion. Health Educ J. 2003;62: 5-22.

12. Matterne U, Egger N, Tempes J, Tischer C, Lander J, Dierks M-L, et al. Health literacy in the general population in the context of epidemic or pandemic coronavirus outbreak situations: Rapid scoping review. Patient Educ Couns. 2020.

13. Samerski S. Health literacy as a social practice: Social and empirical dimensions of knowledge on health and healthcare. Soc Sci Med. 2019;226: 1-8.

14. Fitrina KM, Baiquni F, Supriyati S. Community engagement strategy for healthy diet in urban community: A phenomenological study. 2020 [cited 20 Jan 2021].

15. Gautam V, S D, Rustagi N, Mittal A, Patel M, Shafi S, et al. Health literacy, preventive COVID 19 behaviour and adherence to chronic disease treatment during lockdown among patients registered at primary health facility in urban Jodhpur, Rajasthan. Diabetes Metab Syndr. 2020;15: 205-211.

16. Fitrina KM, Baiquni F, Supriyati S. Community 
engagement strategy for healthy diet in urban community: A phenomenological study. 2020 [cited 20 Jan 2021].

17. Dunn P, Conard S. Improving health literacy in patients with chronic conditions: A call to action. Int J Cardiol. 2018;273: 249-251.

18. Gabel P, Larsen MB, Edwards A, Kirkegaard P, Andersen B. Knowledge, attitudes, and worries among different health literacy groups before receiving first invitation to colorectal cancer screening: Cross-sectional study. Prev Med Rep.
2019;14: 100876.

19. Örsal Ö, Duru P, Örsal Ö, Tırpan K, Çulhacı A. Analysis of the relationship among health awareness and health literacy, patient satisfaction levels with primary care in patients admitting to primary care health centers. Patient Educ Couns. 2019;102: 376-382.

20. Baquni F, Fitrina KM, Supriyati S. Who are the actual beneficiaries of health promotion? An evaluation of health promotion scope in Yogyakarta. 2020 [cited 20 Jan 2021]. 